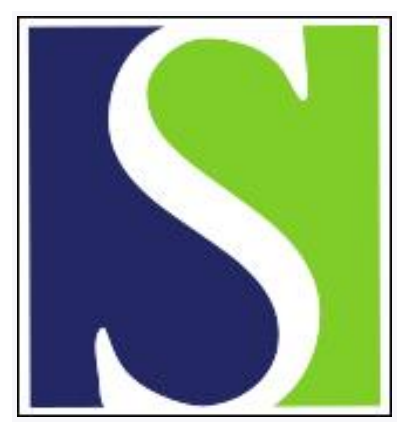

Scand J Work Environ Health 2007;33(3):192-197

https://doi.org/10.5271/sjweh.1126

Issue date: 30 Jun 2007

Work disability absence among young workers with respect to earnings losses in the following year

by Breslin FC, Tompa E, Zhao R, Amick III BC, Pole JD, Smith P, Hogg-Johnson S

Affiliation: Institute for Work \& Health, 481 University Avenue, Suite 800, Toronto, Ontario, M5G 2E9, Canada. cbreslin@iwh.on.ca

Key terms: cost of illness; earnings loss; employment; health economics; injury; occupational health; occupational illness; work disability absence; young worker

This article in PubMed: www.ncbi.nlm.nih.gov/pubmed/17572828 


\title{
Work disability absence among young workers with respect to earnings losses in the following year
}

\author{
by F Curtis Breslin, PhD, ${ }^{1,2}$ Emile Tompa, PhD, ${ }^{1,2,3}$ Ryan Zhao, MSc, ${ }^{1}$ Benjamin C Amick III, PhD, ${ }^{1,4}$ \\ Jason D Pole, MSc, ${ }^{1,2}$ Peter Smith, MPH, ${ }^{1,5,6}$ Sheilah Hogg-Johnson, PhD ${ }^{1,2}$
}

\begin{abstract}
Breslin FC, Tompa E, Zhao R, Amick III BC, Pole JD, Smith P, Hogg-Johnson S. Work disability absence among young workers with respect to earnings losses in the following year. Scand J Work Environ Health 2007;33(3):192197.
\end{abstract}

\begin{abstract}
Objectives The primary objective of this study was to evaluate the earnings losses that young workers experience in the year after a work disability absence.

Methods The sample consisted of workers aged 16 to 24 years from a longitudinal survey of a representative sample of Canadians. Young workers who lost $\geq 5$ days of work due to work disability or illness (ie, work disability absence) were matched to uninjured controls on the basis of age, gender, preabsence earnings, and student status. This matching procedure resulted in 173 cases and 795 controls. The outcome measure was the difference in earnings the year after the work disability episode between injured cases and their uninjured controls.

Results An analysis of variance indicated that young workers experiencing a work disability absence had significantly fewer earnings than their controls in the year after the absence $(\mathrm{P}<0.05)$. This earnings loss was not due to between-group differences in school activity or workhours in the year after the work absence.

Conclusions No study to date has estimated the impact of work-related disability on earnings trajectories among young workers. The findings of the present study indicate that earnings losses can occur among young workers even during their transition into the labor market. Documenting the economic impacts of work injuries early in one's worklife can provide information for policy debates on the allocation of resources to control workplace hazards where teenagers and young adults work and debates on the determination of fair and adequate benefits for young workers.
\end{abstract}

Key terms cost of illness; employment; health economics; injury; occupational health; occupational illness; youth.

Occupational injury and illness among adolescents and young adults are a public health concern. In 2003, 186220 workers in the United States between the ages of 15 and 24 years in private industry sustained a workplace injury that led to at least 1 day of lost work (1). Fifteen percent of the injuries sustained by adolescents at work resulted in permanent impairment, such as chronic pain, scarring, sensory loss, or loss of range of motion (2). Twenty-six percent of injured adolescents have reported ongoing medical problems associated with their injury (3).
Even though the health consequences of work injury among young workers have received much attention, no studies based on individual data have estimated the economic consequences associated with these injuries. A study of teenage occupational injuries estimated the direct (eg, medical costs, workplace disruption) and indirect (eg, lifetime earnings losses) costs to be USD 5 billion in 1993 (4). However, this study did not specifically estimate lost earnings. Instead, income loss was assumed to be what legal cases of compensation typically award.

Institute for Work \& Health, Toronto, Canada.

Department of Public Health Sciences, University of Toronto, Toronto, Canada.

Department of Economics, McMaster University, Toronto, Canada.

School of Public Health, University of Texas Health Science Center at Houston, Houston, Texas, United States.

Institute of Medical Science, University of Toronto, Toronto, Canada.

Center for Research on Inner City Health, St Michaels Hospital, Toronto, Canada.

Reprint requests to: Dr Curtis Breslin, Institute for Work \& Health, 481 University Avenue, Suite 800, Toronto, Ontario, M5G 2E9, Canada. [E-mail: cbreslin@iwh.on.ca] 
Studies on the economic losses of adult workers show that both temporary and permanent disability lead to earnings losses (5-7). For example, adults with permanent disability claims earned $40 \%$ less after their injury (5). Among adult workers, people who had at least four lost days of temporary work disability were projected to have lost about USD 800 per year in earnings over a 10-year period (6).

There are several reasons to study the economic losses of young injured workers specifically. Adolescents and young adults have significantly higher work injury rates than other age groups (8-10). In addition, a work disability occurring early in one's worklife can have a greater impact on one's career and earnings when compared with a disability occurring later in one's worklife. In addition, since young workers are also in a school-to-work transition period and may have fewer family responsibilities than adult workers, the injury may be an impetus to return to school to prepare for another type of job (if one is unable to continue in an occupation due to a disability).

Long-term economic losses from temporary disability due to work injuries could arise for a variety of reasons. For instance, a long-term physical disability might have ensued, but was not deemed compensable according to the workers' compensation system. Work absences due to work injuries may also be stigmatized by employers and co-workers. In addition, the work absence could have led to missing valuable work experience (6). With young workers in particular, one would also need to evaluate the possibility that reduced postinjury earnings were the result of an increase in school involvement.

Our objective in this study was to evaluate the earnings losses that young workers may experience after an episode of work disability. Assessing the short-term economic losses of young people after a work injury provides an indication of whether work injuries influence the initial earnings trajectory. A secondary objective was to assess differences in school activity and workhours after work disability absences, if income differences between disabled workers and controls were found.

\section{Study population and methods}

\section{Design and study population}

Begun in 1993, the Survey of Labour and Income Dynamics (SLID) is a longitudinal survey of representative samples of Canadian households (11). It is designed to capture changes in the economic well-being of individuals and families over time with a specific focus on labor market experiences, income, and family dynamics. The

survey consists of a series of 6-year panels, a new panel being introduced every 3 years to replace the oldest panel. This study used the three panels started in 1993 , 1996, and 1999. Data up to 2000 for all of the three SLID panels show that $95 \%$ to $96 \%$ of the prior-year sample continues to participate from 1 year to the next (11).

The target population for the SLID is all persons living in Canada, excluding people in the Yukon or Northwest Territories, residents of institutions, persons living on reserves, and full-time members of the Canadian Armed Forces living in barracks. Each panel contains approximately 15000 households with about 31000 respondents aged $\geq 16$ years. Our study focused on respondents 16 to 24 years of age during the period 1993 to 2003.

Respondents are interviewed annually in January to collect labor market information from the preceding 12 months. During this interview, they are asked about their work experiences over the previous calendar year on a monthly basis. Respondents are asked to give permission for their tax files to be accessed for income information for the corresponding period (ie, wages and salary). If permission to access tax file information is not given, the respondents are re-interviewed again in May to collect this income information.

Cases were defined as young workers who experienced a work disability absence and had at least 3 years of annual earnings information (ie, year prior to the absence, year of absence, year postabsence). Work disability absence refers to an absence of $\geq 1$ week due to a work-related illness or disability.

From 1993 to 2003, a total of 389 young workers met our case definition. A total of 161 respondents were excluded due to the rotating panel design and the fact that respondents lacked pre- and postabsence information (ie, right or left censored). Another 55 respondents were excluded due to missing preabsence information on our key matching variables (matching procedure described in a later section) or postabsence income. These exclusions left 173 respondents with work disability absences for analysis.

The 55 respondent cases that were excluded were more likely to be male (74.6\%) and from the first and third panels (36.4\% from each panel). Their average preabsence age was 19.1 (SD 2.5) years, and the preabsence income was CAD 9268 (SD 11 040).

\section{Measures}

Age. Age was defined as months from date of birth to the point of the young worker's absence.

Gender. The sex of the respondent was either female or male. 
School activity. The school-activity variable indicated whether the respondent was attending school, college, CEGEP (a French acronym meaning college of general and vocational education), or a university in the reference year or not. School activity at the time of the work absence was used as a matching variable. In addition, school activity in the calendar year after the work absence was part of our secondary analyses to examine what factors may have contributed to any earnings losses.

Annual earnings. The annual earnings data were primarily based on the linkage with the respondent's tax files (12). However, a small percentage of the respondents provided their annual earnings information during the interview in May. We calculated earnings for the calendar year prior to, the year of, and the year after the work absence.

The SLID designers handled missing income information differently depending on the household response pattern. Households from which no one responded in a given year were left as missing income. In partially responding households, the SLID staff imputed income data using a nearest neighbor approach (12). Although we retained the imputed incomes prior to any work absence, any postabsence imputations of income were set as missing, since the work absence could have influenced the variables used when the postabsence income was imputed.

Hours worked. For the secondary analyses of the potential reasons behind any income differences, we also used the total number of workhours in the calendar year after the work absence to calculate the proportion of a full-time equivalent, with 2000 hours in a year equaling 1.0 full-time equivalents.

\section{Matching controls to cases}

We used a matched case-control design to estimate the earnings a worker would have received had they not been injured. In other words, we compared the postabsence earnings of a disabled worker with those of a comparison group who had not experienced a work disability absence.

Our matching procedure followed a two-stage process. The cases and controls were matched on the basis of age, gender, school activity (the month of the absence), and income in the calendar year prior to the absence. First, we randomly selected a case and matched it with control candidates on the basis of gender and school activity at the time point of the absence (ie, exact matching of these variables).

Second, we identified potential controls on the basis of similar age and income to each case by initially excluding those with a greater than 6-month age difference or a greater than $20 \%$ preabsence earnings difference. Those not meeting these criteria were not candidate controls for that particular case. We then used the following formula to calculate the distance between the cases and the potential controls:

$$
\begin{aligned}
& \mathrm{D}_{\text {case-control }}=
\end{aligned}
$$

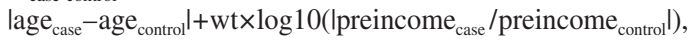

where age is months at the point of absence, preincome is the earnings in the calendar year before the absence, and $w t$ is the weight adjusted by $w t=$ maximum allowed age difference $/ \log 10(1+$ maximum allowed preincome difference).

The potential controls with the smallest distance from the cases were selected first. Following recommendations by Durkheim (13), we selected a maximum of five controls for each case. This matching process resulted in 173 cases being matched-with $83.2 \%$ of them having five controls, $5.2 \%$ having four controls, and $11.6 \%$ having three controls or fewer-for a total of 795 controls.

\section{Analytic approach used for the earnings difference}

Our dependent variable was the difference between each case and their respective controls. We examined the distribution of the difference scores and found them to follow an approximately normal distribution with a kurtosis value of 0.77 and a skewness value of -0.24 , the normal distribution values being close to zero (14).

Due to the matching process, a case and its controls represented blocks of nonindependent observations. To deal with this circumstance, we utilized a "treatment" by blocks analysis of variance (ANOVA) (15), each set of a case and controls representing a block. This model was defined as follows:

$$
\mathrm{Y}_{\mathrm{ij}}-\mathrm{Y}_{\text {control }}=\mu . .+\lambda_{\mathrm{j}}+\varepsilon_{\mathrm{ij}},
$$

where $Y_{i j}$ was the postabsence earnings, $\mu$.. was the general mean, $\rho_{i}$ was the effect of a work disability absence, $\lambda_{\mathrm{j}}$ was the effect of each block of a case and controls, and $\varepsilon_{\mathrm{ij}}$ was the error term. Given that the dependent variable was a difference score, whether the intercept differs significantly from zero is the test of differences between the cases and controls. We used the traditional threshold of $\mathrm{P}<0.05$ in defining a significant difference.

\section{Analytic approach for the secondary analyses}

To assess any between-group differences in hours worked (full-time equivalents), a similar ANOVA was used with the blocks procedure. To examine differences in the proportion of respondents in school between the cases and controls, we performed a chi-square test. 


\section{Results}

Table 1 presents the descriptive statistics for the cases (preabsence) and controls. On the average, these young workers were 21.5 (SD 2.1) years old. More than $60 \%$ were male, and $33.5 \%$ were attending either high school or postsecondary school. The virtually identical average preabsence income between the cases and controls indicates that the matching procedure was effective in selecting comparable controls. The standard deviation for preabsence income was substantial because it represented both the variation within the case-control blocks and the variation between the blocks. In addition, as has already been noted, the dependent variable in our ANOVA was the difference in earnings between the cases and controls.

The earnings results are presented graphically in figure 1. This figure shows the mean (before deduction) earnings of the workers who had a work disability absence and the controls over time as predicted by the model controlling for within-matching variation. Before the injury, the mean earnings of disabled workers and their controls were indistinguishable due to the fact that preabsence earnings was a matching variable.

The ANOVA model showed the postabsence difference to be statistically significant (the F-value for the model being 6.90, with a P-value of 0.009). During the year following the absence, the mean difference in earnings between the cases and controls was CAD 1015 (95\% CI 257-1773). This is a substantial sum when one takes into consideration how little the workers were earnings in this early stage of their worklife (ie, cases earned $6.7 \%$ less than the controls).

\section{Secondary analyses}

We were able to explore two possible explanations for the between-group differences in postabsence earnings. One possible explanation is that, to retrain for a different job or career, proportionally more disabled workers became students in the year after their absence. However, we found that the percentage of workers who were also students did not differ statistically significantly between the disabled workers and their controls (35.8\%

Table 1. Characteristics of the cases and controls in the year before the work absence.

\begin{tabular}{|c|c|c|c|c|c|c|c|c|c|c|c|c|c|c|c|c|c|c|c|c|c|c|}
\hline & \multirow{2}{*}{\multicolumn{2}{|c|}{$\begin{array}{c}\text { Age } \\
\text { (year) }\end{array}$}} & \multirow{2}{*}{\multicolumn{2}{|c|}{$\begin{array}{l}\text { Preabsence } \\
\text { income } \\
\text { (CAD) }\end{array}$}} & \multirow{2}{*}{\multicolumn{2}{|c|}{$\begin{array}{l}\text { Male } \\
(\%)\end{array}$}} & \multirow{2}{*}{\multicolumn{2}{|c|}{$\begin{array}{c}\text { Student } \\
(\%)\end{array}$}} & \multicolumn{6}{|c|}{ Marital status } & \multirow{2}{*}{\multicolumn{2}{|c|}{$\begin{array}{l}\text { Living in } \\
\text { urban area } \\
(\%)\end{array}$}} & \multicolumn{6}{|c|}{ Highest education milestone } \\
\hline & & & & & & & & & \multicolumn{2}{|c|}{$\begin{array}{l}\text { Living } \\
\text { in a rela- } \\
\text { tionship }\end{array}$} & \multicolumn{2}{|c|}{$\begin{array}{l}\text { Living } \\
\text { previously } \\
\text { in a rela- } \\
\text { ship }^{b}\end{array}$} & \multicolumn{2}{|c|}{ Single } & & & \multicolumn{2}{|c|}{$\begin{array}{l}\text { Less } \\
\text { than } \\
\text { high } \\
\text { shool }\end{array}$} & \multicolumn{2}{|c|}{$\begin{array}{l}\text { Complet- } \\
\text { ed } \\
\text { high } \\
\text { shool }\end{array}$} & \multicolumn{2}{|c|}{$\begin{array}{c}\text { Complet- } \\
\text { ed college } \\
\text { or } \\
\text { university }\end{array}$} \\
\hline & Mean & SD & Mean & SD & N & $\%$ & $\mathrm{~N}$ & $\%$ & $\mathrm{~N}$ & $\%$ & $\mathrm{~N}$ & $\%$ & N & $\%$ & N & $\%$ & N & $\%$ & $\mathrm{~N}$ & $\%$ & $\mathrm{~N}$ & $\%$ \\
\hline Cases (N 173) & 21.5 & 2.1 & 11102 & 8983 & 110 & 63.6 & 58 & 33.5 & 41 & 23.7 & 5 & 2.9 & 127 & 73.4 & 117 & 67.6 & 42 & 25.3 & 80 & 48.2 & 44 & 26.5 \\
\hline Controls (N 795) & 21.5 & 2.1 & 10961 & 8585 & 499 & 62.8 & 267 & 33.6 & 152 & 19.1 & 19 & 2.4 & 624 & 78.5 & 606 & 76.2 & 138 & 18.3 & 379 & 50.1 & 239 & 31.6 \\
\hline
\end{tabular}

a Married or common law.

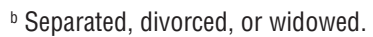

\section{Predicted mean income}

( $95 \%$ confidence interval)

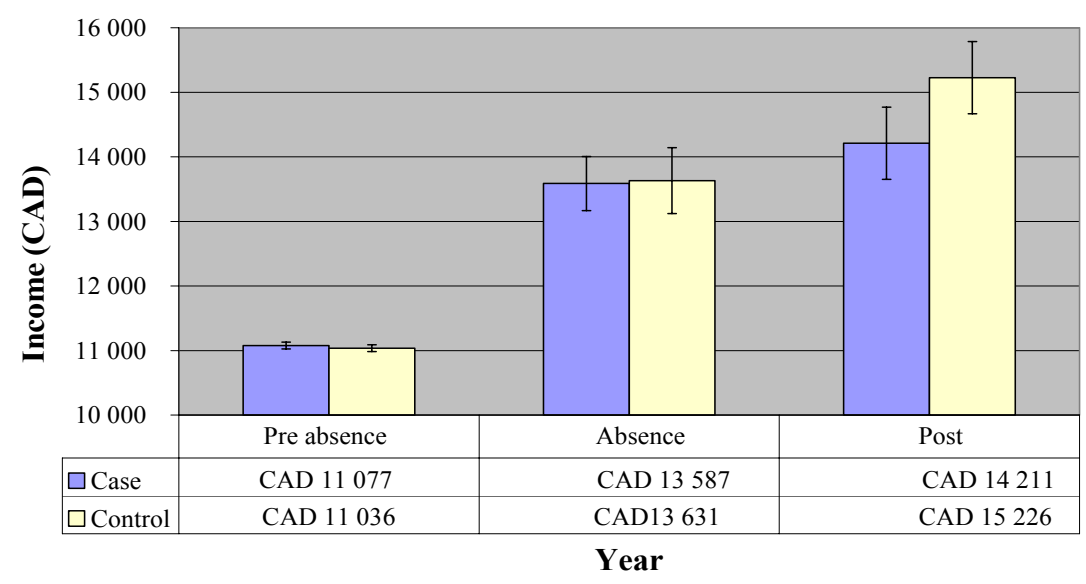

Figure 1. Earnings for the cases and controls in the calendar years before, during, and after the work absence. 
and $40.8 \%$, respectively) $($ chi-square $=1.43, \mathrm{P}$-value $=$ $0.23)$.

We also examined the possibility that disabled workers did not work the same number of hours as the controls. This reduction might have occurred, for example, because of health reasons related to the work disability absence. The average hours worked by disabled workers and controls (converted into full-time equivalents with 2000 hours each year equaling full-time work) were 0.73 (SD 0.44) and 0.75 (SD 0.44), respectively. Our analyses of variance found no statistically significant difference between the groups $(\mathrm{F}$-value $=0.19, \mathrm{P}$-value $=0.66)$.

\section{Discussion}

Our findings show that workdays lost due to workplace injuries and illnesses lead to lost earnings for young workers in the year following the event. This degree of earnings loss is generally in line with that found among adult workers with temporary disability (6). Our estimates of the economic consequences are based on work disability absences of $\geq 5$ workdays. Consequently, the degree to which shorter absences influence subsequent earnings remains to be determined.

We examined a few possible explanations for these postdisability earnings losses. We did not find a change in educational activity among the young workers who experienced a work disability when they were compared with those who did not. In addition, young workers who experienced a work disability absence reported working a similar number of hours as their nondisabled counterparts. The lack of differences with respect to these factors seems to suggest that the young workers who experienced a disability earned less per hour in the year after their disability.

Unlike older workers, these young workers did not show an earnings decrement the year of the work disability absence. This finding may be due to the fact that it is common for young people to work temporary and part-time jobs, meaning that even uninjured young workers have significant periods of unpaid "absences". In addition, adults may have longer absence durations leading to a greater impact on injured adult worker earnings.

The study findings need to be considered in light of certain methodological limitations. The outcome measure did not provide information on the nature or severity of the disability. This information would have allowed us to provide more detail on the differential impact of these types of work disability absences. Nevertheless, taking $\geq 5$ days off work would appear to suggest that the injury was reasonably serious. A related issue is that the ability to take a week off work due to a disability is not only dependent on the severity of the injury or illness. In other words, equally severe injuries may result in some people taking a week off work and others not-the differences being due to financial needs, work arrangements, and the like. These types of misspecification errors would probably lead to an underestimate of between-group differences. Finally, due to the nature of the panel survey design, the temporal profile of postabsence earnings was short (ie, year after the absence).

To ascertain whether to disproportionately target prevention resources towards young workers, we need more research to determine how persistent these earnings losses are. There is the possibility that the negative impact of work disability on earnings could disappear sooner with young workers than with older, more established workers.

If such earnings losses persist, the problem may be a consideration for compensation systems because work disability absences among young workers occur as their income trajectory is still increasing. From an equity perspective, workers' compensation programs that are based on current pay at an entry level job would not take into account the fact that young workers are making a transition into the labor market. Of course, this implication awaits further research on the nature and duration of earnings losses due to work disability in this age group.

In summary, young workers who experience work disability show earnings losses in the year after the injury. An important issue for future research is to determine how long such earnings losses persist. A better understanding of the extent to which these losses are related to residual work disability, injury-related job loss, or the stigma attached to work disability is also a useful question for future research.

\section{Acknowledgments}

This study was supported by a grant from the National Institute of Occupational Health and Safety (R03OH008126-01). In addition, Peter Smith was supported by a strategic training research fellowship from the Canadian Institutes for Health Research Strategic Training Program in the Transdisciplinary Approach to the Health of Marginalized Populations.

\section{References}

1. Bureau of Labor Statistics. Workplace injuries and illnesses in 2003. Washington (DC): Department of Labor; 2004. Report no USDL 04-2486.

2. Parker DL, Carl WR, French LR, Martin FB. Characteristics of adolescent work injuries reported to the Minnesota Department 
of Labor and Industry. Am J Public Health. 1994;84(4):60611.

3. Parker DL, Carl WR, French LR, Martin FB. Nature and incidence of self-reported adolescent work injury in Minnesota. Am J Ind Med. 1994;26:529-41.

4. Miller TR, Waehrer GM. Costs of occupational injuries to teenagers, United States. Inj Prev. 1998;4(3):211-7.

5. Reville RT. The impact of a disabling workplace injury on earnings and labor force participation. In: Haltiwanger JC, Lane JI, Spletzer JR, Theeuwes JM, Troske KR, editors. The creation and analysis of employer-employee matched data. New York (NY): Elsevier; 1999. p 147-73.

6. Boden LI, Galizzi M. Economic consequences of workplace injuries and illnesses: lost earnings and benefit adequacy. Am J Ind Med. 1999;36(5):487-503.

7. Reville RT, Boden LJ, Biddle J, Mardesich C. An evaluation of New Mexico workers' compensation permanent partial disability and return to work. Santa Monica (CA): RAND Institute for Civil Justice; 2001.

8. Laflamme L, Menckel E. Aging and occupational accidents: a review of the literature of the last three decades. Saf Sci.
$1995 ; 21: 145-61$.

9. Salminen S. Have young workers more injuries than older ones?: an international literature review. J Saf Res. 2004;35:513-21.

10. Breslin F, Smith P. Age-related differences in work injuries: a multivariate, population based study. Am J Ind Med. 2005;48:50-6.

11. Statistics Canada. Survey of labour and income dynamics: microdata user's guide. Ottawa (Ontario): Statistics Canada; 1997.

12. Armstrong B, House G. Data quality in the 2003 Survey of Labour and Income Dynamics. Ottawa: Statistics Canada; 2005. Research Income Paper Series 75F0002MIE, volume 4.

13. Gail M, Williams R, Byar DP, Brown C. How many controls? J Chronic Dis 1976;29:723-31.

14. SAS Institute Inc. SAS/STAT user's guide. Version 8. Cary (NC): SAS Institute Inc; 2001.

15. Keppel G. Design and analysis: a researcher's handbook. 2nd ed. Englewood Cliffs (NJ): Prentice Hall; 1982.

Received for publication: 29 May 2006 